Zhou Quanlai (Orcid ID: 0000-0001-7887-3686)

Daryanto Stefani (Orcid ID: 0000-0001-6264-9401)

Wang Yongcui (Orcid ID: 0000-0003-0922-0571)

Liu Minghu (Orcid ID: 0000-0003-4691-8266)

\title{
Responses of secondary wind dispersal to environmental characteristics and diaspore morphology of seven Calligonum species
}

Quanlai Zhou ${ }^{1}$, Zhimin Liu ${ }^{1}$, Zhiming Xin ${ }^{2}$, Stefani Daryanto ${ }^{3,4}$, Lixin Wang ${ }^{5}$ Xuehua, Li $^{1}$,

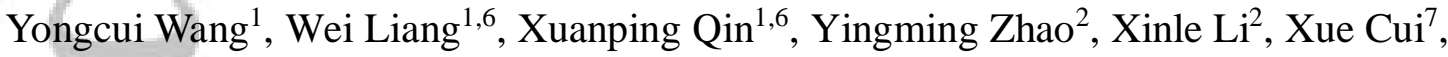
Minghu Liu*,2<smiles>C1CCC1</smiles>

${ }^{1}$ Institute of Applied Ecology, Chinese Academy of Sciences, 72 Wenhua Road, Shenyang

110016, China

${ }^{2}$ Experimental Center of Desert Forestry, Chinese Academy of Forestry, 1 Tuanjie Road,

Dengkou 015200, China

${ }^{3}$ State Key Laboratory of Earth Surface Processes and Resources Ecology, Faculty of Geographical Science, Beijing Normal University, Beijing 100875, China

This is the author's manuscript of the article published in final edited form as:

Zhou, Q., Liu, Z., Xin, Z., Daryanto, S., Wang, L., Li, X., ... Liu, M. (2019). Responses of secondary wind dispersal to environmental characteristics and diaspore morphology of seven Calligonum species. Land Degradation \& Development. https://doi.org/10.1002/1dr.3489 
${ }^{4}$ Institute of Land Surface System and Sustainable Development, Faculty of Geographical Science, Beijing Normal University, Beijing 100875, China

${ }^{5}$ Department of Earth Sciences, Indiana University-Purdue University Indianapolis (IUPUI),

Indianapolis, Indiana 46202, USA

${ }^{6}$ University of Chinese Academy of Sciences, 19 Yuquan Road, Beijing 100049, China

${ }^{7}$ Station of Forest and Grassland Pest Control and Quarantine, Liaoning Province,

Shenyang 110804, China

*Corresponding author: Minghu Liu

Experimental Center of Desert Forestry, Chinese Academy of Forestry, 1 Tuanjie Road,

Dengkou 015200, China

Tel.: $+86-478-7967123$

E-mail:slzxlmh@sina.com

This article is protected by copyright. All rights reserved. 


\section{Summary}

Secondary diaspore dispersal by wind, i.e. wind-driven movement along the ground surface, is important for the structure and dynamics of plant populations and communities. However, how wind velocity (WV), ground surface (GS) and diaspore morphology influence diaspore secondary dispersal by wind are unclear. We used a wind tunnel and video camera to measure the threshold of wind velocity (TWV) and diaspore velocities (DV) of secondary diaspore dispersal. Diaspores of seven Calligonum species with different appendages (wings, bristles, membranous balloon, and wings+thorns) were used to determine the TWV and DV under variable wind speed $(4,6,8$, and $10 \mathrm{~m} / \mathrm{s})$ and four GSs (cement, sand, loam, and gravel). GS and diaspore morphological traits explained $37.1 \%$ and $18 \%$ of diaspore TWV, respectively. Meanwhile, WV, GS, and diaspore morphological traits explained $62.4 \%, 13.6 \%$, and $3.2 \%$ of DV, respectively. An increasing trend was shown for TWV and a decreasing trend was shown for DV in the order of cement, sand, loam, and gravel surfaces. Spherical and light diaspores had low TWV and high DV, while winged and heavy diaspores had high TWV and low DV. Our results indicated that adaptive features of diaspore appendages might be the result of selection for primary dispersal or secondary dispersal. The mechanism of diaspore secondary dispersal is important for understanding the recovery of degraded sand dunes and providing theoretical support for restoration practices.

Keywords: adaptive features; diaspore morphology traits; diaspore velocity; threshold wind velocity; wind tunnel 


\section{Introduction}

Secondary dispersal by wind along the soil surface is a key life-history stage for anemochorous plants, and it occurs after the initial diaspore dispersal from the parent plant (Schurr, Bond, Midgley, \& Higgins, 2005). Secondary wind dispersal may be more important than primary dispersal with respect to long-distance movement and final seedling establishment (Schurr, Bond, Midgley, \& Higgins, 2005; Vander Wall \& Joyner, 1998), secondary wind dispersal largely influences the structure and dynamics of plant populations and communities in the landscape (Damschen et al., 2014; Sutherland et al., 2013). Using model simulation, previous studies showed that secondary wind dispersal may be markedly affected by diaspore morphology, the characteristics of the ground surface (GS), and wind conditions (Greene \& Johnson, 1997; Nathan et al., 2011; Nathan \& Muller-Landau, 2000; Vander Wall, Kuhn, \& Beck, 2005). However, few studies have quantitatively examined the relationships between diaspore traits, wind conditions, surface characteristics, and diaspore secondary wind dispersal.

Diaspore traits are closely related to diaspore dispersal by wind (Nathan et al., 2011; Vander Wall \& Joyner, 1998). Particular diaspore appendages are assumed to help wind-dispersed diaspores to travel (Jongejans \& Telenius, 2001; Nathan et al., 2011). It is generally deemed that the morphological traits of diaspores are an adaptation for a specific mode of dispersal (Andersen, 1993; Vander Wall \& Joyner, 1998). Previous studies have investigated the effect of diaspore traits on the probability of secondary dispersal and dispersal distance (Emmerson, Facelli, Chesson, \& Possingham, 2010; Vander Wall \& Joyner, 1998). However, few studies have been conducted on how the diaspore traits influence secondary diaspore dispersal. Therefore, the appendage structures (AS), shape, mass, and aerodynamic characteristics of diaspores should be considered when exploring the 
mechanism of secondary dispersal of diaspores.

Addressing the relationships between soil surface characteristics and diaspore secondary dispersal by wind is fundamental to understand the process of anemochorous plant colonization (Garcia, Klein, \& Jordano, 2017). The drag or shear force exerted by wind for diaspore initial motion is called the threshold shear stress (He \& Ohara, 2017), while the corresponding wind speed is called the threshold wind velocity (TWV) or critical wind speed (He \& Ohara, 2017; Negyesi, Loki, Buro, \& Szabo, 2016). Diaspore velocity (DV) reflects the ability of diaspores to travel a sufficient distance if the wind speed is higher than the diaspore TWV (Gomez-Aparicio, Gomez, \& Zamora, 2007; Seidler \& Plotkin, 2006). The diaspore TWV and DV are important factors in evaluating the dispersal ability of diaspores in heterogeneous environments (Gomez-Aparicio, 2008; Schurr et al., 2005). Studies have demonstrated that the surface texture and coarseness might change the mechanical resistance of diaspore movement along the surface (Schurr et al., 2005). Further, coarse surfaces can decrease the wind speed on the soil surface (Damschen et al., 2014; Levin, Ben-Dor, Kidron, \& Yaakov, 2008). However, it remains unclear how diaspore TWV and DV relate to diaspore morphology, aerodynamic traits, and surface characteristics (Sutherland et al., 2013). One possible reason is the practical difficulties in monitoring the movement and distribution of diaspores under natural conditions (Jones \& Muller-Landau, 2008; Jongejans \& Telenius, 2001).

The genus Calligonum has many anemochorous shrubs that are successful pioneers for sand stabilization and vegetation restoration on mobile sand dunes, stabilized sand dunes, and the Gobi Desert (Fan, McHugh, et al., 2018; Gautam \& Bishnoi, 1990; Juma, Zhao, \& Wang, 2018; Ren \& Tao, 2005; Shi, Zhao, Kong, \& Pan, 2013; Ying \& Guan, 2008). There are 22 species of Calligonum distributed in Inner Mongolia, Gansu, Ningxia, and Xinjiang provinces of China (Abdurahman, Sabirhazi, Liu, Yin, \& Pan, 2012). Their secondary dispersal 
characteristics can be determined by the large inter-specific difference in diaspore appendage type and structure (wings, bristles, balloon, and wings+thorns) (Abdurahman et al., 2012; Feng, Pan, \& Shen, 2010). Considering that the diaspores also have a relatively high inter-specific variation in diaspore shape and mass (Gouja et al., 2015; Juma et al., 2018; Shi, Wen, \& Pan, 2016), they are ideal subjects for examining the relationship between diaspore morphology and secondary dispersal by wind.

The objectives of this study were to determine 1) how the surface characteristics affect diaspore TWV and DV in secondary dispersal by wind, and 2) how diaspore traits affect diaspore TWV and DV. Diaspore mass and appendage type as well as surface texture and coarseness might strongly affect diaspore TWV and DV. Since greater force is needed to move diaspores with high diaspore mass (Maddox \& Carlquist, 1985), we predicted that high diaspore mass leads to high TWV and produces low DV. Previous research has documented that anemochorous diaspore appendages are not only for wind dispersal, but they are also important for lodging in soil crevices or entrapment in depressions (Maddox \& Carlquist, 1985; Vander Wall \& Joyner, 1998). We predicted that diaspores lodged or trapped in ground surface (GS) play a leading role in increasing diaspore TWV.

\section{Materials and Methods}

\subsection{Diaspore collection}

We collected dry diaspores of Calligonum aphyllum, C. densum, C. junceum, C. klementzii, and $C$. rubicundum in Tazhong $\left(83^{\circ} 40^{\prime} \mathrm{E}, 39^{\circ} 00^{\prime} \mathrm{N} ; 1099 \mathrm{~m}\right.$ a.s.l.) in the Taklimakan Desert, Xinjiang, and of $C$. arborescens and C. mongolicum in the Ulanbuh Desert $\left(40^{\circ} 09^{\prime}-40^{\circ} 57^{\prime} \mathrm{N}\right.$, $106^{\circ} 09^{\prime}-107^{\circ} 10^{\prime} \mathrm{E} ; 1050 \mathrm{~m}$ a.s.1.) of Inner Mongolia, northwestern China (Fig 1). For each 
species, we collected 400 intact diaspores from 20 individual plants in July and August, 2016. All diaspores were air dried and preserved in a laboratory for experiments. Diaspores of the genus Calligonum are achenes with four types of appendages (wings, bristles, balloon, and wings+thorns) (Abdurahman et al., 2012; Zhou et al., 2019). Pictures of diaspores, methods for measuring morphological and aerodynamic traits of the tested diaspores and their characteristics are showed in Zhou et al., 2019.

\subsection{Simulation of ground surfaces in the wind tunnel}

A wind tunnel (with a test section of $2 \mathrm{~m}$ height, $2 \mathrm{~m}$ width, and $20 \mathrm{~m}$ length) was used for measuring the secondary dispersal process and distribution pattern of diaspores (Dauer, Mortensen, \& Humston, 2006; Zhu, Liu, Xin, Zhao, \& Liu, 2016). We used a cement floor with a relatively smooth and hard surface as the control. Sand, loam, and gravel, which were taken from a sand dune, farm land, and riverbed, respectively, were paved on the testing section $(8 \mathrm{~cm})$ in the wind tunnel to simulate the GS of an active sand dune, farm land, and Gobi Desert, respectively. The sand and loam were sieved through a $2 \mathrm{~mm}$ sieve to remove gravel and large pieces of plant material.

\subsection{Measurement of wind profile on different ground surfaces}

A pitot tube (160-96, Dwyer Instruments, Inc., Indiana, USA) and a differential pressure transmitter (Dwyer Instruments, Inc., Indiana, USA) were used to measure the wind velocity (WV) in the wind tunnel. We used the WV at an axis of the wind tunnel $(1 \mathrm{~m}$ distance from the side walls and floor) as the free-stream WV because it was the least affected by the side walls (Zhang, Dong, Zhao, Yuan, \& Han, 2008). Each wind profile were determined by 
measuring the wind velocities above the floor at $1,3,7,10,20,30,50,70$, and $100 \mathrm{~cm}$. In total, 16 wind profiles were determined at free-stream wind speeds of $4,6,8$, and $10 \mathrm{~m} / \mathrm{s}$, and four ground surfaces of cement, sand, loam, and gravel.

\subsection{Measurement of diaspore threshold wind velocity on four ground surfaces}

A row of 10 diaspores (spaced $3 \mathrm{~cm}$ apart) from the same species was placed on each ground surface (GS) (>50 cm from the sidewalls). The diaspores were observed through a glass shield when the wind velocity was gradually increased from $0 \mathrm{~m} / \mathrm{s}$. Once a diaspore moved, a corresponding WV was recorded. The observations ended when all 10 diaspores moved. Thus, 10 values of WV were recorded in total. The experiment for each species was repeated five times (with 50 diaspores) on each ground surface (Fig. 1).

\section{Fig. 1 here}

\subsection{Measurement of diaspore velocity on the ground surface}

In the test section, a row of 10 diaspores (spaced $3 \mathrm{~cm}$ apart) from the same species was placed on a GS in the middle of the tunnel (Fig. 1). A wind-proof cover was used to prevent diaspores from being blown away. A rope was tied on the cover. A camera was regulated to record the whole view of the test section. Then, the experiment was started at wind velocities of $4,6,8$, or $10 \mathrm{~m} / \mathrm{s}$ (Zhu et al., 2016). When the wind speed reached the test $\mathrm{WV}$, the rope was pulled and the diaspores were moved (by wind) from the starting point. We used the camera to record the whole process. The experiment for each species was repeated five times on each ground surface at each wind velocity. 
The videos were analyzed frame by frame using Quick Time Player. There were three scenarios for the diaspores, namely (1) standing still, (2) passing the finish line, and (3) stopping before the finish line. For the first scenario, the DV was $0 \mathrm{~m} / \mathrm{s}$. For the second scenario, the DV was calculated as follows:

$D V=\frac{D}{T}$

here, $D$ is the distance $(5 \mathrm{~m})$, and $T$ is the diaspore traveling time.

For the third scenario, we measured the distance that the diaspore traveled from the starting point to where it stopped. By analyzing the videos, we found that the time required for the diaspores to travel ranged from $0.84 \mathrm{~s}$ to $8.68 \mathrm{~s}$ per $5 \mathrm{~m}$. Thus, we used $10 \mathrm{~s}$ as the traveling time to calculate their velocity to make sure that their velocity was lower than that of any diaspore passing the finish line. Thus, the DV in the third scenario was defined as follows:

$D V=\frac{D^{\prime}}{T^{\prime}}$

here, $D^{\prime}$ is the distance from the starting point to where they stopped, and $T^{\prime}$ is $10 \mathrm{~s}$.

\subsection{Data analysis}

Redundancy analysis (RDA) was conducted using Canoco 5.0 (version 5.0, Microcomputer Power, Ithaca, NY, USA) (Tackenberg, 2003) to determine the relationship between the explanatory variables of wind velocity (WV), appendage structures (AS), shape index (SI), diaspore mass, wind loading (WL), terminal velocity (TV), and ground surface (GS) and response variables of the diaspore threshold wind velocity (TWV) and diaspore velocity (DV) of the seven Calligonum species.

Since the four types of AS and GS were not scaled attributes, we defined four variables for the occurrence of $\mathrm{AS}$, namely $\mathrm{AS}_{1}, \mathrm{AS}_{2}, \mathrm{AS}_{3}$, and $\mathrm{AS}_{4}$, with the property of $\mathrm{AS}_{\mathrm{i}}=1$ if the AS is wings $\left(\mathrm{AS}_{1}\right)$, bristles $\left(\mathrm{AS}_{2}\right)$, balloon $\left(\mathrm{AS}_{3}\right)$, and wings+thorns $\left(\mathrm{AS}_{4}\right)$; otherwise, $\mathrm{AS}_{\mathrm{i}}=0$. 
Further, we defined four variables for the GS as $\mathrm{GS}_{1}$ (cement), $\mathrm{GS}_{2}$ (sand), $\mathrm{GS}_{3}$ (loam), and $\mathrm{GS}_{4}$ (gravel). Each explanatory variable was tested to assess the contribution of two environmental factors (WV and GS) and five diaspore morphology factors (diaspore mass, TV, WL, SI, and AS) to the variation in the TWV and DV using forward-selection procedures.

Descriptive statistics were obtained and ANOVA was performed using PASW Statistics Software version 18.0 (IBM Corp., Armonk, New York, USA). A box plot and line-scatter plots were drawn using SigmaPlot version 10.0 (Systat Software, Inc., USA).

\section{Results}

\subsection{Wind profiles on four ground surfaces}

The four ground surface (GS) types mainly influenced wind velocity (WV) within 0-30 cm above the ground before WV levelled off. Wind velocity was greatest on cement surface and decreased on sand, loam and gravel surface (Fig. 2). For example, on the cement surface, the WV was $2.3,3.4,4.6$, and $5.8 \mathrm{~m} / \mathrm{s}$ at wind speeds of $4,6,8$, and $10 \mathrm{~m} / \mathrm{s}$, respectively, at $1 \mathrm{~cm}$ above the surface. However, at $1 \mathrm{~cm}$ above the loam surface, the WV was $0.8,1.3,2.9$, and $4.1 \mathrm{~m} / \mathrm{s}$, respectively, at $1 \mathrm{~cm}$ above the gravel surface, it was $0.2,0.4,0.4$, and $0.6 \mathrm{~m} / \mathrm{s}$, respectively.

Fig. 2 here 


\subsection{Threshold wind velocity of seven Calligonum species on four ground surfaces}

Ground surface (GS) had a significant effect on the diaspore threshold wind velocity (TWV, $p<0.01)$. The TWV of diaspores increased in the order of cement, sand, loam, and gravel surfaces $(p<0.05$; Fig. 3). Significant differences in the TWV were shown among different species $(p<0.01)$. Calligonum arborescens had the lowest TWV on all GS, except on cement surface. In contrast, $C$. rubindicum always generated the highest TWV regardless of GS (Fig.

$3)$.

Fig. 3 here

Fig. 4 here

We equally divided the TWVs of diaspores into four groups from lowest to highest in each species to compare difference of average TWV between adjacent groups (Fig. 4). The TWVs in the group of $0 \%-25 \%$ corresponded to the diaspores that were easiest to move among the 50 diaspores. Accordingly, the group of $75 \%-100 \%$ of the TWVs corresponded to the diaspores that were the most difficult to move. On the cement surface, the TWVs in the four groups increased linearly in each species. However, on the sand surface, the TWVs changed significantly between the groups of 50\%-75\% and $75 \%-100 \%$ in C. rubicundum, C. aphyllum, and C. mongolicum because there were five, three, and two diaspores lodged in the surface, respectively. On the loam surface, changes occurred in $C$. aphyllum and $C$. rubicundum because there were six and two diaspores lodged on the surface, respectively. On the gravel surface, changes occurred in C. aphyllum, C. junceum, C. klementzii, and $C$. rubicundum owing to seven, three, one, and eleven diaspores lodged or trapped in the surface, 
respectively (Fig. 4).

\subsection{Relationships between diaspore threshold wind velocity, ground surface, and} diaspore morphological traits

\section{Fig. 5 here}

The ground surface (GS), appendage structure (AS), shape index (SI), wing loading (WL), terminal velocity (TV), and diaspore mass explained $55.3 \%$ of the variation in the threshold wind velocity (TWV). The presence of gravel surface was positively related to TWV, and explained $29.7 \%(p=0.002)$ of the variation. The presence of cement and sand surfaces had negative effect on TWV, and explained $7.2 \%(p=0.002)$ and $0.2 \%(p=0.002)$ of the total variation, respectively. The presence of bristles or wings were negatively related to TWV, and explained $1.4 \%(p=0.002)$ and $0.3 \%(p=0.002)$ of the total variation, respectively. The presence of wings+thorns and diaspore mass were positively related to TWV, and explained $16.2 \%(p=0.002)$ and $0.1 \%(p=0.05)$ of the total variation, respectively (Fig. 5; Table 1).

Table 1 here

\subsection{Diaspore velocity of seven Calligonum species on four ground surfaces}

At WV of $4 \mathrm{~m} / \mathrm{s}$, most diaspores were motionless, except for $C$. mongolicum, $C$. aphyllum, $C$. junceum, C. arborescens, C. klementzii, and C. densum on the cement surface. As WV increased to $6 \mathrm{~m} / \mathrm{s}$, fewer diaspores remained motionless, such as C. rubicundum on sand 
surface, C. rubicundum, C. aphyllum, and C. densum on loam surface, and C. aphyllum, $C$.

arborescens, C. junceum, C. klementzii, C. mongolicum, and C. rubicundum on gravel surface.

As WV increased to $8 \mathrm{~m} / \mathrm{s}$, all diaspores moved and the diaspore velocity (DV) of the seven species increased with WV (Fig. 6).

Fig. 6 here

3.5 Relationship between wind velocity, ground surface, diaspore morphological trait, and diaspore threshold wind velocity

The WV, GS, AS, TV and WL explained $79.2 \%$ of the variation in DV. The presence of WV and cement surface had a positive effect on DV, and explained $62.4 \%(p=0.002)$ and $12.1 \%$ ( $p=0.002$ ) of the variation in DV. The presence of sand and gravel surface, wings+thorns, and TV and WL were negative related to DV, and explained $1.0 \%(p=0.002), 0.5 \%(p=0.002), 2.8 \%$ $(p=0.002), 0.3 \%(p=0.002)$, and $0.3 \%(p=0.002)$ of the total variation, respectively (Fig. 5;

Table 1).

Fig. 7 here

Table 2 here

\section{Discussion}

This article is protected by copyright. All rights reserved. 


\subsection{Effect of ground surface and diaspore morphological trait on diaspore threshold wind velocity}

Ground surface (GS) made the largest contribution (67.1\%) to diaspore threshold wind velocity (TWV). Gravel, the coarsest GS generated the highest TWV as it increases frictional resistance between the wind and the surface (Field \& Pelletier, 2018). Static friction also increased with increasing surface roughness as diaspore appendages can lodge between the gravel crevices (Maddox \& Carlquist, 1985; Vander Wall \& Joyner, 1998). The above-mentioned two reasons also explain the increasing variation in diaspore TWV with the coarseness of GS (Fig. 4).

In this study, the motionless diaspores that lodged in crevices or were trapped in gaps in coarse surfaces accounted for no more than $25 \%$ of the total diaspores (Fig. 5). For a spherical diaspore (with a low shape index, SI), a low rolling friction resistance is exerted for their initial motion (Cross, 2016). Thus, most spherical diaspores with bristles are less likely to be lodged in crevices. Low ratio of small diaspores was trapped in the GSs because there were not enough large gaps for trapping the diaspores. High static friction diaspores with folded spines, pappus bristles, sharp stiff hairs, hooked bracts, and dense hair can increase ratio of diaspores lodged in crevices (Maddox \& Carlquist, 1985). However, our results showed that the ratio of lodged diaspores with wings+thorns, wings, balloon, and bristles was $28 \%, 14 \%, 6 \%$, and $2 \%$ of total number of diaspores on coarsest surface (gravel), respectively. Therefore, our results did not support the prediction that diaspores lodged or 
trapped in GS play a leading role in determining diaspore TWV.

\subsection{Effect of wind velocity and ground surfaces on diaspore velocity}

Wind velocity (WV), particularly near-surface WV, was the most important factor for diaspore secondary dispersal by wind, consistent with previous studies (Nathan et al., 2002; Tackenberg, 2003). Wind velocity profile (WVP), a distribution curve of wind velocity with height, is an important characteristic of wind (Schurr et al., 2005). On smooth and horizontal surfaces, the shape of the WVP tends to be a straight line owing to less air friction (Schurr et al., 2005; Zhang et al., 2008). On coarse surfaces, the shape of the WVP tends to be a curve owing to the high friction of the surface to wind (Lv \& Dong, 2012).

In this study, when the free-stream WV was increased to $8 \mathrm{~m} / \mathrm{s}$, more than $75 \%$ of the diaspores were dispersed rapidly. Namely, regardless of the surface or diaspore morphological traits, a WV of $8 \mathrm{~m} / \mathrm{s}$ might be critical for most anemochorous plants in mobile sand dunes, semi-stabilized sand dunes, and the Gobi Desert with sparse distribution of shrubs (Fan, Zhou, et al., 2018). In the desert ecosystem, the wind velocity profile is largely influenced by ground surface rather than vegetation (Schurr et al., 2005). However, the TWV of more than $50 \%$ of $C$. rubicundum diaspores was higher than the critical wind velocity (Fig. 5). The possible reason is that the TWV was determined using gradually increased WV, while, the DV was determined using wind gust. Diaspores might exert more drag under wind gust than that under gradually increased WV because wind gust might have more impulse than gradually increased WV. 


\subsection{Adaptation of diaspores to secondary dispersal}

Ecologists have long acknowledged the importance of different diaspore dispersal strategies

(Levin, Muller-Landau, Nathan, \& Chave, 2003; van Oudtshoorn \& van Rooyen, 1999), represented by diaspore morphology and its adaptive features such as diaspore mass. The diaspore mass is probably consistent with previous result of selection either for diaspore dispersal or seedling survival (Andersen, 1993). The species of Calligonum used in this study are shrubs with low variation in plant height. The light diaspores (e.g., C. mongolicum and $C$. junceum) with low TWV and high DV were good dispersers. They can disperse further and occupy suitable environments, hence, facilitating interchange of species and restoration of biodiversity between neighboring habitat patches (Aavik \& Helm, 2018). However, heavier diaspores (e.g., C. rubicundum or C. arborescens) with high TWV and low DV are poor dispersers. Their high diaspore mass increases seedling colonization and seedling survival, therefore, adapting to local competitive environments and promoting local vegetation restoration (Rousset \& Gandon, 2002).

Adaptive features such as the shape of diaspore appendages might be the result of the selection of dispersal modes either for primary dispersal or secondary dispersal. Spherical diaspores with bristles (e.g., C. mongolicum and C. arborescens) had low TWV and high DV in secondary dispersal. Meanwhile, diaspores with wings or wings+thorns (e.g., C. aphyllum and C. rubicundum) had high TWV and low DV in secondary dispersal. Therefore, spherical diaspores might be suitable for secondary dispersal owing to their low motion resistance on 
the soil surface, e.g., rippled fields of sand dunes, Gobi desert, or farm lands. Diaspores with wings might disperse further when falling from the mother plant owing to the fact that wind exerts a higher drag force on the diaspore. Therefore, diaspores with wings might be more suitable for primary rather than secondary dispersal.

\section{Conclusions}

Coarseness of ground surfaces greatly influences the variation in diaspore threshold wind velocity and diaspore velocity. Near-surface wind velocity is the most important factor for diaspore velocity in diaspore secondary dispersal by wind. We found that wind velocity of 8 $\mathrm{m} / \mathrm{s}$ might be the threshold value for rapid dispersal of large diaspores of anemochorous plants on ground surfaces in open fields. Diaspore appendages might be a trade-off of large diaspores between primary dispersal or secondary dispersal by wind. The study is important for understanding mechanisms of diaspore secondary dispersal by wind and providing data support for restoration of degraded sand dunes.

\section{Acknowledgements}

We thank Zhigang Wang for technical support in wind tunnel experiment and valuable comments on the manuscript, to Junliang Gao, Fengmei Luo, Batu Gegen, Jingbo Zhang, Lu Hai, Yaru Huang, Cheng Ge, Na Duan and Ruibing Duan for assisting with diaspore 
collections and technical support in measurements in Experimental Center of Desert Forestry,

Chinese Academy of Forestry. This study was supported by National Natural Science

Foundation of China (41571270). We would like to thank Editage (www.editage.cn) for

English language editing. We are grateful for the detailed and constructive comments from

two anonymous reviewers, which significantly improved the readability and quality of this

manuscript.

\section{Authors' contributions}

ZL, ML and QZ conceived the ideas and designed methodology; SD and LW contributed to the ideas on the writing and edited the manuscripts; ZX, WL, XQ and XC collected the data; XL, YW, YZ and XL analyzed the data; QZ led the writing of the manuscript, all authors contributed critically to the drafts and gave final approval for publication. The authors declare no conflicts of interest.

\section{References}

Aavik, T., \& Helm, A. (2018). Restoration of plant species and genetic diversity depends on landscape-scale dispersal. Restoration Ecology, 26, S92-S102. doi:10.1111/rec.12634

Abdurahman, M., Sabirhazi, G., Liu, B., Yin, L., \& Pan, B. (2012). Comparison of five Calligonum species in tarim basin based on morphological and molecular data. Excli Journal, 11, 776-782. 
Andersen, M. C. (1993). Diaspore morphology and seed dispersal in several wind-dispersed Asteraceae. American Journal of Botany, 80(5), 487-492. doi:10.2307/2445362

Cross, R. (2016). Coulomb's law for rolling friction. American Journal of Physics, 84(3), 221-230. doi:10.1119/1.4938149

Damschen, E. I., Baker, D. V., Bohrer, G., Nathan, R., Orrock, J. L., Turner, J. R., . . . Tewksbury, J. J. (2014). How fragmentation and corridors affect wind dynamics and seed dispersal in open habitats. Proceedings of the National Academy of Sciences of the United States of America, 111(9), 3484-3489. doi:10.1073/pnas.1308968111

Dauer, J. T., Mortensen, D. A., \& Humston, R. (2006). Controlled experiments to predict horseweed (Conyza canadensis) dispersal distances. Weed Science, 54(3), 484-489. doi:10.1614/ws-05-017r3.1

Emmerson, L., Facelli, J. M., Chesson, P., \& Possingham, H. P. (2010). Secondary seed dispersal of Erodiophyllum elderi, a patchily distributed short-lived perennial in the arid lands of Australia. Austral Ecology, 35(8), 906-918. doi:10.1111/j.1442-9993.2009.02097.x

Fan, B., McHugh, A. D., Guo, S., Ma, Q., Zhang, J., Zhang, X., . . Zhao, C. (2018). Factors influencing the natural regeneration of the pioneering shrub Calligonum mongolicum in sand dune stabilization plantations in arid deserts of northwest China. Ecology and Evolution, 8(5), 2975-2984. doi:10.1002/ece3.3913

Fan, B., Zhou, Y., Ma, Q., Yu, Q., Zhao, C., \& Sun, K. (2018). The bet-hedging strategies for seedling emergence of Calligonum mongolicum to adapt to the extreme desert 
environments in northwestern China. Frontiers in Plant Science, 9. doi:10.3389/fpls.2018.01167

Feng, Y., Pan, B., \& Shen, G. (2010). Revision of two species of Calligonum from the desert of Xinjiang, Northwestern China. Journal of Arid Land, 2(3), 231-234. doi:10.3724/sp.j.1227.2010.00231

Field, J. P., \& Pelletier, J. D. (2018). Controls on the aerodynamic roughness length and the grain-size dependence of aeolian sediment transport. Earth Surface Processes and Landforms, 43(12), 2616-2626. doi:10.1002/esp.4420

Garcia, C., Klein, E. K., \& Jordano, P. (2017). Dispersal processes driving plant movement: challenges for understanding and predicting range shifts in a changing world. Journal of Ecology, 105(1), 1-5. doi:10.1111/1365-2745.12705

Gautam, D. D., \& Bishnoi, S. (1990). Allelopathic effects of some desert plants on seed-germination and seedling growth of Calligonum-polygonoides L. Annals of Arid Zone, 29(3), 191-195.

Gomez-Aparicio, L. (2008). Spatial patterns of recruitment in Mediterranean plant species: linking the fate of seeds, seedlings and saplings in heterogeneous landscapes at $\begin{array}{lllll}\text { different } & \text { scales. Journal of Ecology, 96(6), 1128-1140. }\end{array}$ doi:10.1111/j.1365-2745.2008.01431.x

Gomez-Aparicio, L., Gomez, J. M., \& Zamora, R. (2007). Spatiotemporal patterns of seed dispersal in a wind-dispersed Mediterranean tree (Acer opalus subsp granatense): implications for regeneration. Ecography, 30(1), 13-22. 
doi:10.1111/j.2006.0906-7590.04658.x

Gouja, H., Garnatje, T., Hidalgo, O., Neffati, M., Raies, A., \& Garcia, S. (2015). Physical mapping of ribosomal DNA and genome size in diploid and polyploid North African Calligonum species (Polygonaceae). Plant Systematics and Evolution, 301(6), 1569-1579. doi:10.1007/s00606-014-1183-9

Greene, D. F., \& Johnson, E. A. (1997). Secondary dispersal of tree seeds on snow. Journal of Ecology, 85(3), 329-340. doi:10.2307/2960505

He, S., \& Ohara, N. (2017). A new formula for estimating the threshold wind speed for snow movement. Journal of Advances in Modeling Earth Systems, 9(7), 2514-2525. doi: $10.1002 / 2017 \mathrm{~ms} 000982$

Jones, F. A., \& Muller-Landau, H. C. (2008). Measuring long-distance seed dispersal in complex natural environments: an evaluation and integration of classical and genetic methods. Journal of Ecology, 96(4), 642-652. doi:10.1111/j.1365-2745.2008.01400.x

Jongejans, E., \& Telenius, A. (2001). Field experiments on seed dispersal by wind in ten umbelliferous species (Apiaceae). Plant Ecology, 152(1), 67-78. doi:10.1023/a:1011467604469

Juma, A., Zhao, X., \& Wang, J. (2018). Changes of seed dormancy of Calligonum junceum in its original habitat. Chinese Journal of Ecology, 37(7), 1952-1958.

Levin, N., Ben-Dor, E., Kidron, G. J., \& Yaakov, Y. (2008). Estimation of surface roughness $(\mathrm{z}(0))$ over a stabilizing coastal dune field based on vegetation and topography. Earth Surface Processes and Landforms, 33(10), 1520-1541. doi:10.1002/esp.1621 
Levin, S. A., Muller-Landau, H. C., Nathan, R., \& Chave, J. (2003). The ecology and evolution of seed dispersal: A theoretical perspective. Annual Review of Ecology Evolution and $\quad$ Systematics, $\quad 34, \quad 575-604$. doi:10.1146/annurev.ecolsys.34.011802.132428

Lv, P., \& Dong, Z. B. (2012). Aerodynamic roughness length of sandy beds and gravel beds. Environmental Earth Sciences, 67(6), 1663-1668. doi:10.1007/s12665-012-1607-1

Maddox, J. C., \& Carlquist, S. (1985). Wind dispersal in californian desert plants: experimental studies and conceptual considerations. Aliso.

Nathan, R., Katul, G. G., Bohrer, G., Kuparinen, A., Soons, M. B., Thompson, S. E., . . Horn, H. S. (2011). Mechanistic models of seed dispersal by wind. Theoretical Ecology, 4(2), 113-132. doi:10.1007/s12080-011-0115-3

Nathan, R., Katul, G. G., Horn, H. S., Thomas, S. M., Oren, R., Avissar, R., . . Levin, S. A. (2002). Mechanisms of long-distance dispersal of seeds by wind. Nature, 418(6896), 409-413. doi:10.1038/nature00844

Nathan, R., \& Muller-Landau, H. C. (2000). Spatial patterns of seed dispersal, their determinants and consequences for recruitment. Trends in Ecology \& Evolution, 15(7), 278-285. doi:10.1016/s0169-5347(00)01874-7

Negyesi, G., Loki, J., Buro, B., \& Szabo, S. (2016). Effect of soil parameters on the threshold wind velocity and maximum eroded mass in a dry environment. Arabian Journal of Geosciences, 9(11). doi:10.1007/s12517-016-2626-0

Ren, J., \& Tao, L. (2005). Effect of conspecific adult plants on the spatial patterns of the soil 
seed bank of Calligonum rubicundum. South African Journal of Botany, 71(1), 61-66. doi:10.1016/s0254-6299(15)30150-2

Rousset, F., \& Gandon, S. (2002). Evolution of the distribution of dispersal distance under distance-dependent cost of dispersal. Journal of Evolutionary Biology, 15(4), 515-523. doi:10.1046/j.1420-9101.2002.00430.x

Schurr, F. M., Bond, W. J., Midgley, G. F., \& Higgins, S. I. (2005). A mechanistic model for secondary seed dispersal by wind and its experimental validation. Journal of Ecology, 93(5), 1017-1028. doi:10.1111/j.1365-2745.2005.01018.x

Seidler, T. G., \& Plotkin, J. B. (2006). Seed dispersal and spatial pattern in tropical trees. Plos Biology, 4(11), 2132-2137. doi:10.1371/journal.pbio.0040344

Shi, W., Wen, J., \& Pan, B. (2016). A comparison of ITS sequence data and morphology for Calligonum pumilum and C. mongolicum (Polygonaceae) and its taxonomic implications. Phytotaxa, 261(2), 157-167. doi:10.11646/phytotaxa.261.2.5

Shi, W., Zhao, Y., Kong, F., \& Pan, B. (2013). Species redress in the Calligonum mongolicum complex (Polygonaceae) - a multidisciplinary approach. Vegetos, 26(1), 249-261. doi:10.5958/j.2229-4473.26.1.036

Sutherland, W. J., Freckleton, R. P., Godfray, H. C. J., Beissinger, S. R., Benton, T., Cameron, D. D., ... Wiegand, T. (2013). Identification of 100 fundamental ecological questions. Journal of Ecology, 101(1), 58-67. doi:10.1111/1365-2745.12025

Tackenberg, O. (2003). Modeling long-distance dispersal of plant diaspores by wind. Ecological Monographs, $73(2)$ 173-189. 
doi:10.1890/0012-9615(2003)073[0173:mldopd]2.0.co;2

van Oudtshoorn, K. v. R., \& van Rooyen, M. W. (1999). Dispersal biology of desert plants. Berlin Heidelberg: Springer

Vander Wall, S. B., \& Joyner, J. W. (1998). Secondary dispersal by the wind of winged pine seeds across the ground surface. American Midland Naturalist, 139(2), 365-373. doi:10.1674/0003-0031(1998)139[0365:sdbtwo]2.0.co;2

Vander Wall, S. B., Kuhn, K. M., \& Beck, M. J. (2005). Seed removal, seed predation, and secondary dispersal. Ecology, 86(3), 801-806. doi:10.1890/04-0847

Ying, F., BoRong, P. A. N., \& GuanMian, S. (2008). Seed morphology of Calligonum sect. Eucauigonum (Polygonaceae) in Xinjiang and its taxonomic significance. Acta Botanica Yunnanica, 30(1), 47-50.

Zhang, Z., Dong, Z., Zhao, A., Yuan, W., \& Han, L. (2008). The effect of restored microbiotic crusts on erosion of soil from a desert area in China. Journal of Arid Environments, 72(5), 710-721. doi:10.1016/j.jaridenv.2007.09.001

Zhou, Q., Liu, Z., Xin, Z., Daryanto, S., Wang, L., Qian, J., . . Liu, M. (2019). Relationship between seed morphological traits and wind dispersal trajectory. Functional plant biology : FPB. doi:10.1071/fp19087

Zhu, J., Liu, M., Xin, Z., Zhao, Y., \& Liu, Z. (2016). Which factors have stronger explanatory power for primary wind dispersal distance of winged diaspores: the case of Zygophyllum xanthoxylon (Zygophyllaceae)? Journal of Plant Ecology, 9(3), 346-356. doi:10.1093/jpe/rtv051 


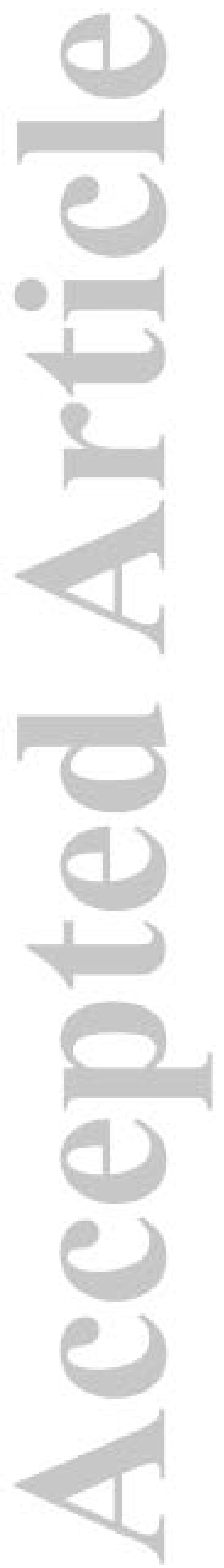

This article is protected by copyright. All rights reserved. 


\section{Tables:}

Table 1 Variation in threshold wind velocity (TWV) explained by ground surfaces (GS) and diaspore morphological traits in seven Calligonum species using redundancy analysis (RDA).

The explanatory variables are ground surface (GS), appendage structures (AS), shape index (SI), diaspore mass (DM), wind loading (WL) and terminal velocity (TV).

\begin{tabular}{lllll}
\hline Factors & Explained variation $(\%)$ & Contribution $(\%)$ & Pseudo-F & $\boldsymbol{p}$ value \\
\hline $\mathrm{GS}_{4}{ }^{*}$ & 29.7 & 53.6 & 592 & 0.002 \\
$\mathrm{AS}_{4}$ & 16.2 & 29.3 & 419 & 0.002 \\
$\mathrm{GS}_{1}$ & 7.2 & 13.1 & 216 & 0.002 \\
$\mathrm{AS}_{2}$ & 1.4 & 2.6 & 44.2 & 0.002 \\
$\mathrm{AS}_{1}$ & 0.3 & 0.6 & 10.0 & 0.002 \\
$\mathrm{GS}_{2}$ & 0.2 & 0.4 & 7.7 & 0.004 \\
$\mathrm{DM}$ & 0.1 & 0.2 & 3.7 & 0.052 \\
Total & 55.3 & 99.8 & & \\
\hline
\end{tabular}

* $\left(\mathrm{AS}_{1}\right)$ wings, $\left(\mathrm{AS}_{2}\right)$ bristles, $\left(\mathrm{AS}_{4}\right)$ wings+thorns, $\left(\mathrm{GS}_{1}\right)$ cement, $\left(\mathrm{GS}_{2}\right)$ sand, $\left(\mathrm{GS}_{4}\right)$ gravel.

*The factors of $\mathrm{AS}_{3}$ (balloon), $\mathrm{GS}_{3}$ (loam), SI, WL and TV were not listed in the table because they were not significant in explaining the variation in TWV. 
Table 2. Variation in diaspore velocity (DV) explained by wind velocity (WV), ground surfaces (GS), appendage structures (AS), shape index (SI), diaspore mass (DM), wind loading (WL) and terminal velocity (TV) in seven Calligonum species using redundancy analysis (RDA).

\begin{tabular}{lllll}
\hline Factors & Explained variation $(\%)$ & Contribution $(\%)$ & Pseudo-F & $\boldsymbol{p}$ value \\
\hline $\mathrm{WV}$ & 62.4 & 78.7 & 9275 & 0.002 \\
$\mathrm{GS}_{1}{ }^{*}$ & 12.1 & 15.2 & 2641 & 0.002 \\
$\mathrm{AS}_{4}$ & 2.8 & 3.6 & 701 & 0.002 \\
$\mathrm{GS}_{2}$ & 0.5 & 0.7 & 133 & 0.002 \\
$\mathrm{GS}_{4}$ & 1.0 & 1.3 & 277 & 0.002 \\
$\mathrm{TV}$ & 0.3 & 0.3 & 74.3 & 0.002 \\
$\mathrm{WL}$ & 0.1 & 0.1 & 31.1 & 0.002 \\
Total & 79.2 & 99.9 & & \\
\hline
\end{tabular}

* $\left(\mathrm{GS}_{1}\right)$ cement, $\left(\mathrm{AS}_{4}\right)$ wings+thorns, $\left(\mathrm{GS}_{2}\right)$ sand, $\left(\mathrm{GS}_{4}\right)$ gravel.

*The factors of $\left(\mathrm{AS}_{1}\right)$ wings, $\left(\mathrm{AS}_{2}\right)$ bristles, $\mathrm{AS}_{3}$ (balloon), $\mathrm{GS}_{3}$ (loam), SI and diaspore mass were not listed in the table because they were not significant in explaining the variation in DV. 


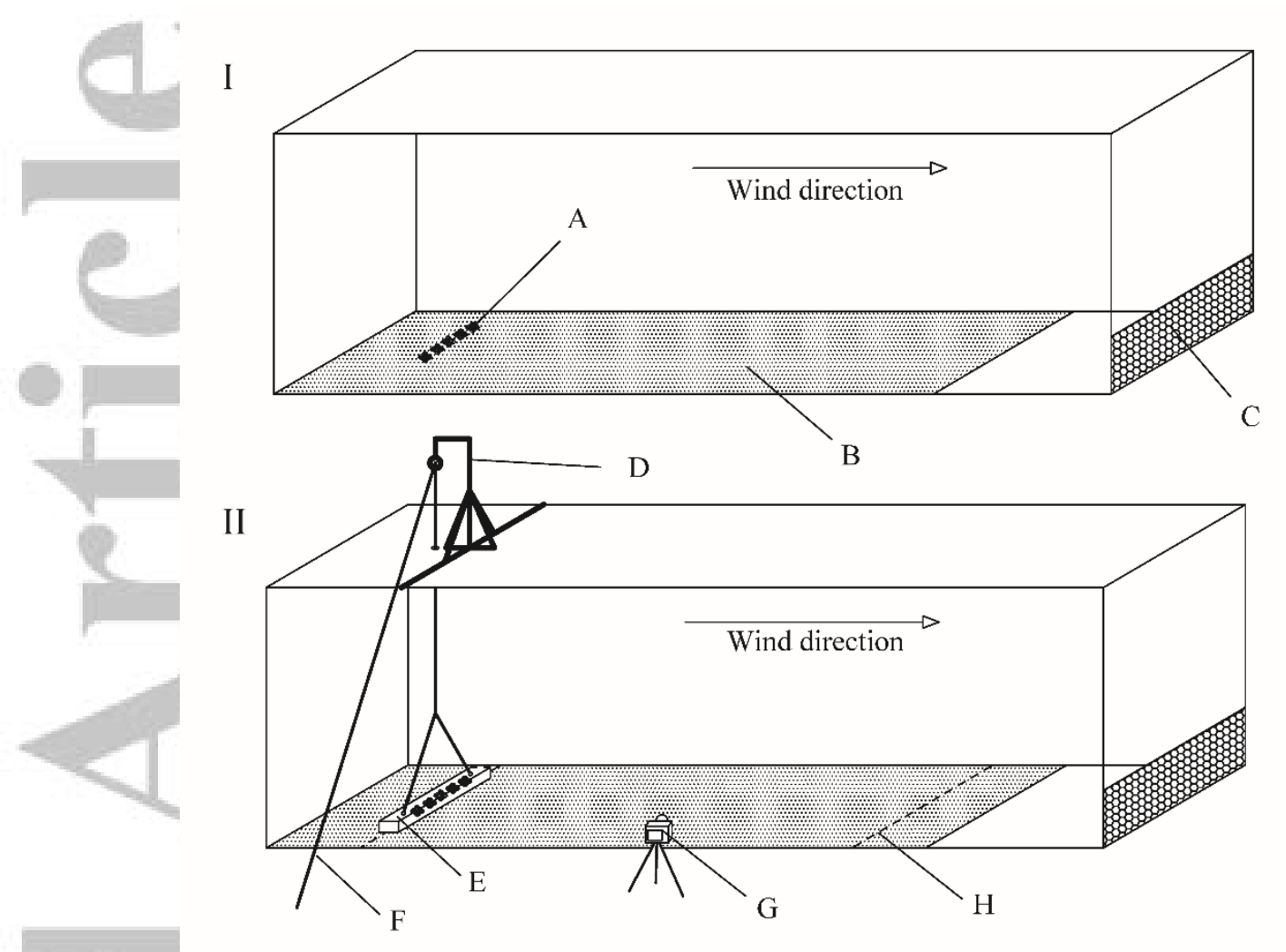

Fig. 1 Diagram of wind tunnel for determining (I) the diaspore threshold wind velocity (TWV) and (II) diaspore velocity (DV) under four wind velocities on four ground surfaces in the wind tunnel. (A) diaspores, (B) ground surface, (C) diaspore-blocking net, (D) support stand, (E) wind-proof cover, $(\mathrm{F})$ pulling rope, $(\mathrm{G})$ camera, and $(\mathrm{H})$ finish line. 


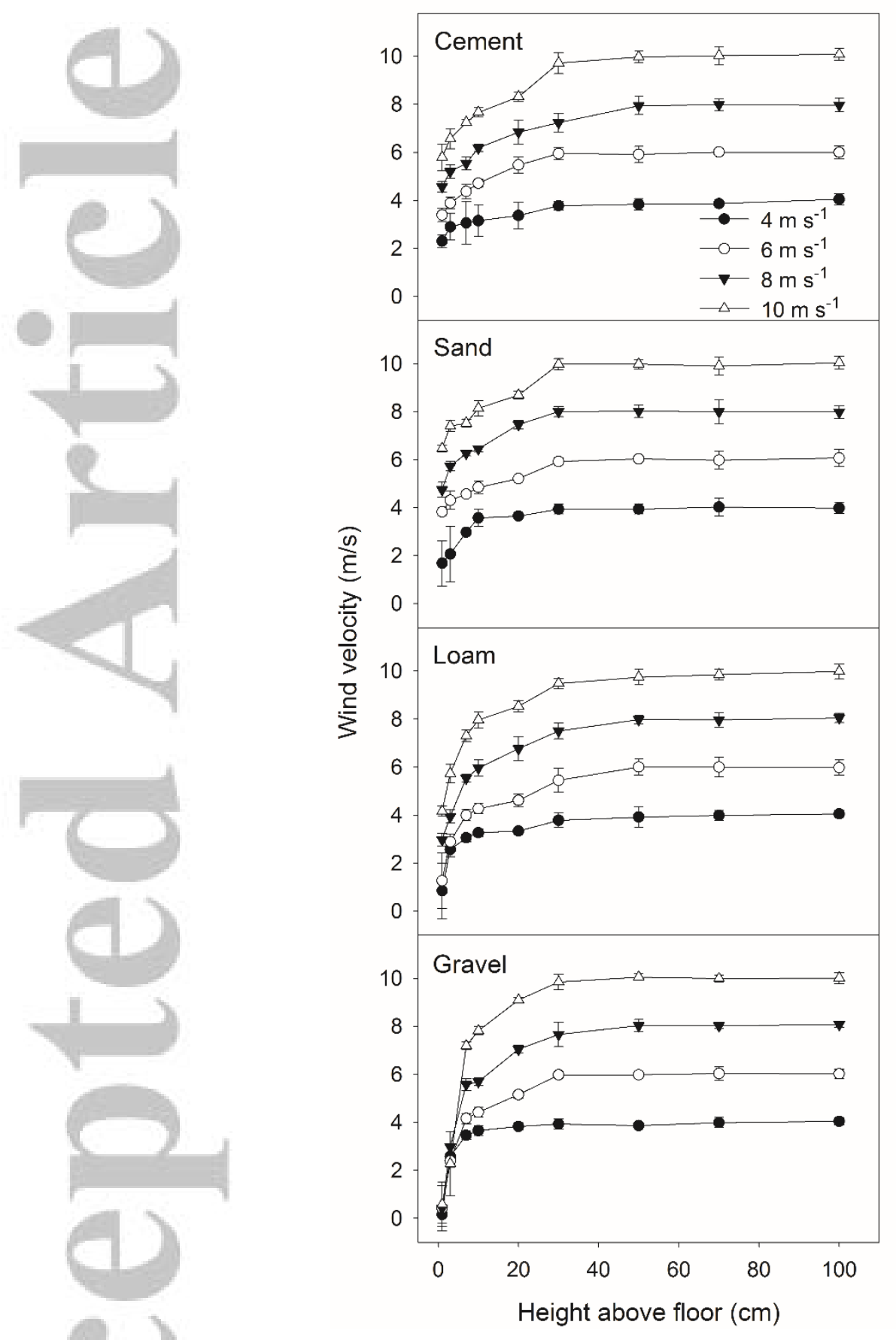

Fig. 2 Wind profiles on four ground surfaces under different wind velocities.

This article is protected by copyright. All rights reserved. 


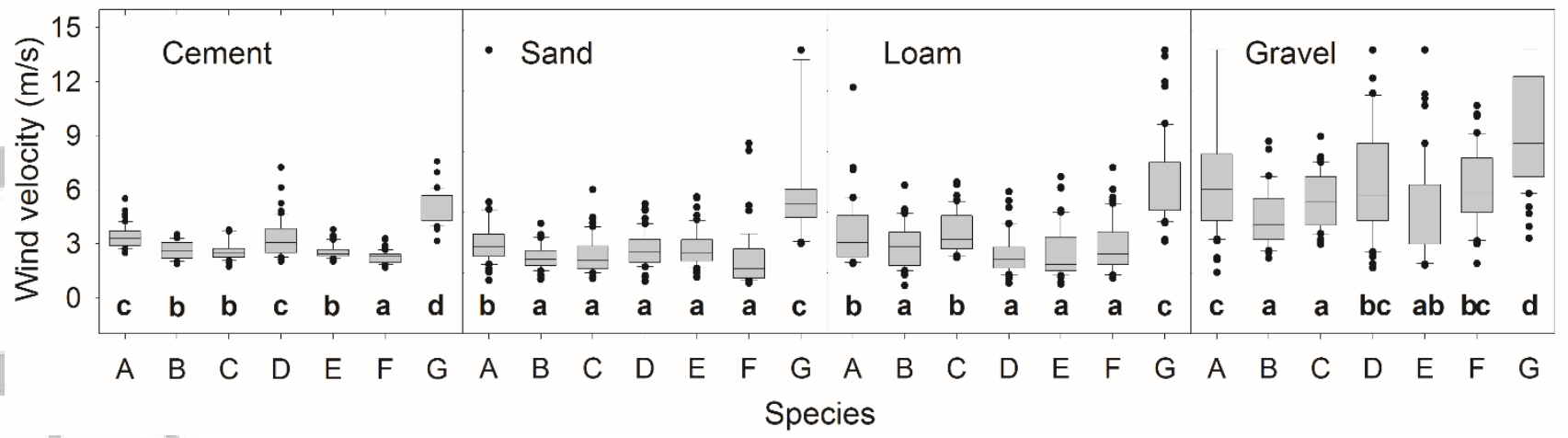

Fig. 3 Threshold wind velocity of seven Calligonum species on four ground surfaces. (A) $C$. aphyllum, (B) C. arborescens, (C) C. densum, (D) C. junceum, (E) C. klementzii, (F) C. mongolicum, and (G) C. rubicundum. Different lowercase letters used to show significant difference of threshold wind velocity of different species on each ground surface. 

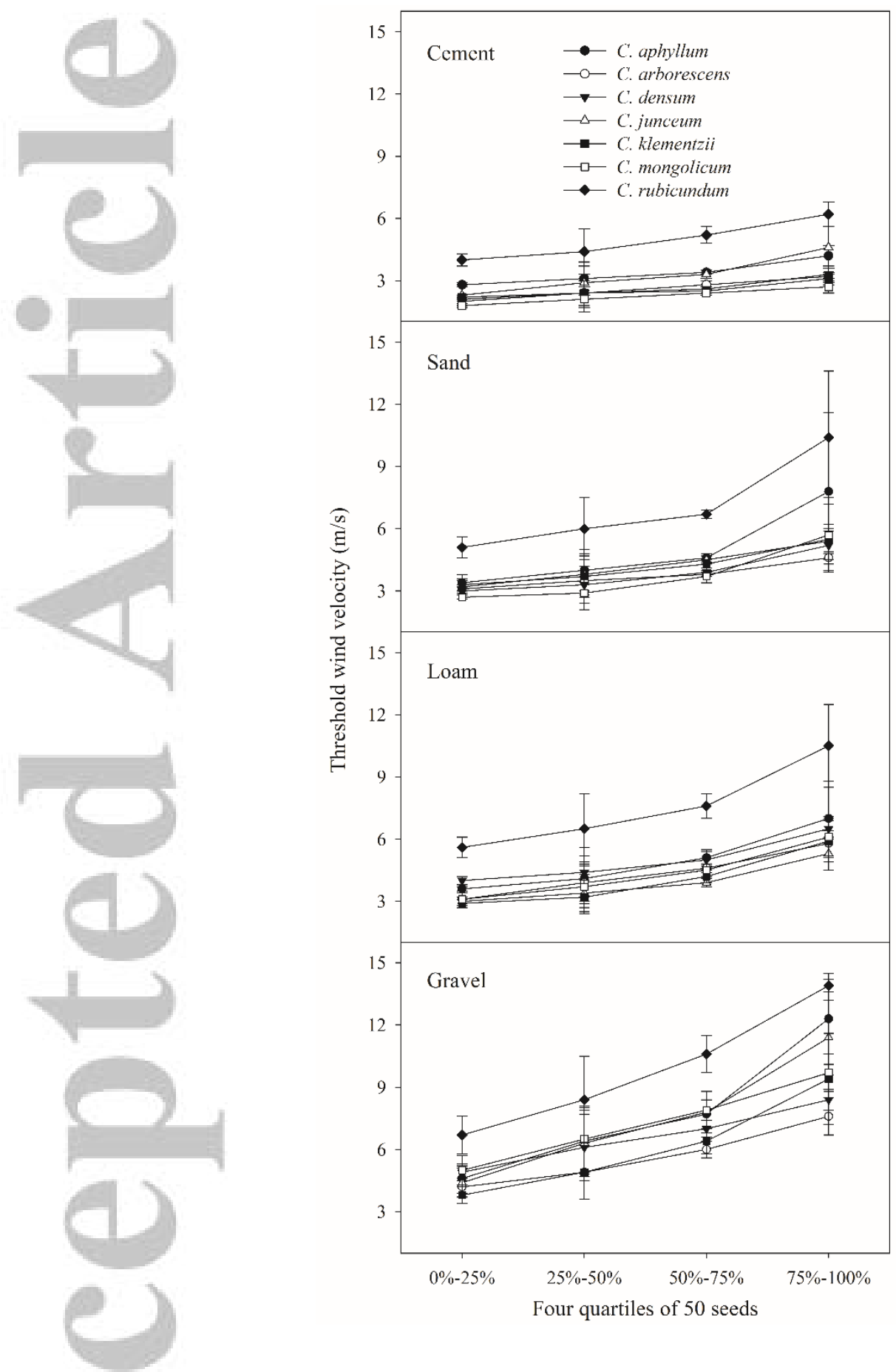

Fig. 4 Differences in threshold wind velocity (TWV) among 0\%-25\%, 25\%-50\%, 50\%-75\%, and $75 \%-100 \%$ of 50 diaspores in each species on four ground surfaces. 


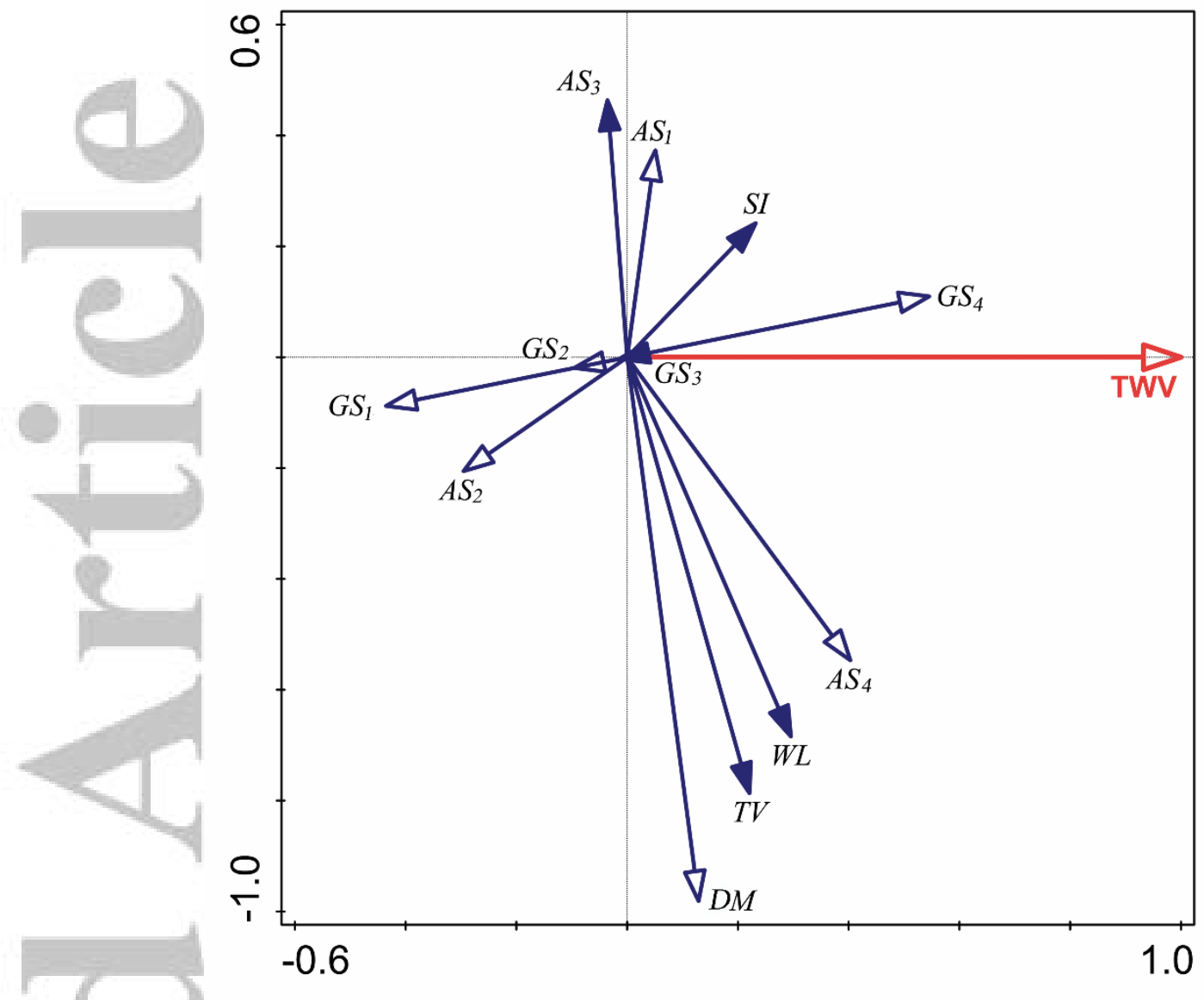

Fig. 5 Relationships between diaspore threshold wind velocity (TWV; m/s), ground surfaces (GS), and diaspore morphological traits. (AS) appendage structures, $\left(\mathrm{AS}_{1}\right)$ wings, $\left(\mathrm{AS}_{2}\right)$ bristles, $\left(\mathrm{AS}_{3}\right)$ balloon, $\left(\mathrm{AS}_{4}\right)$ wings+thorns, $\left(\mathrm{GS}_{1}\right)$ cement, $\left(\mathrm{GS}_{2}\right)$ sand, $\left(\mathrm{GS}_{3}\right)$ loam, $\left(\mathrm{GS}_{4}\right)$ gravel, (DM) diaspore mass $(\mathrm{mg}),(\mathrm{TV})$ terminal velocity $(\mathrm{m} / \mathrm{s}),(\mathrm{WL})$ wing loading $(\mathrm{mg} / \mathrm{cm})$, and (SI) shape index. Red hollow arrows represent the TWV, blue hollow arrows represent significant factors, and blue solid arrows represent non-significant factors. 

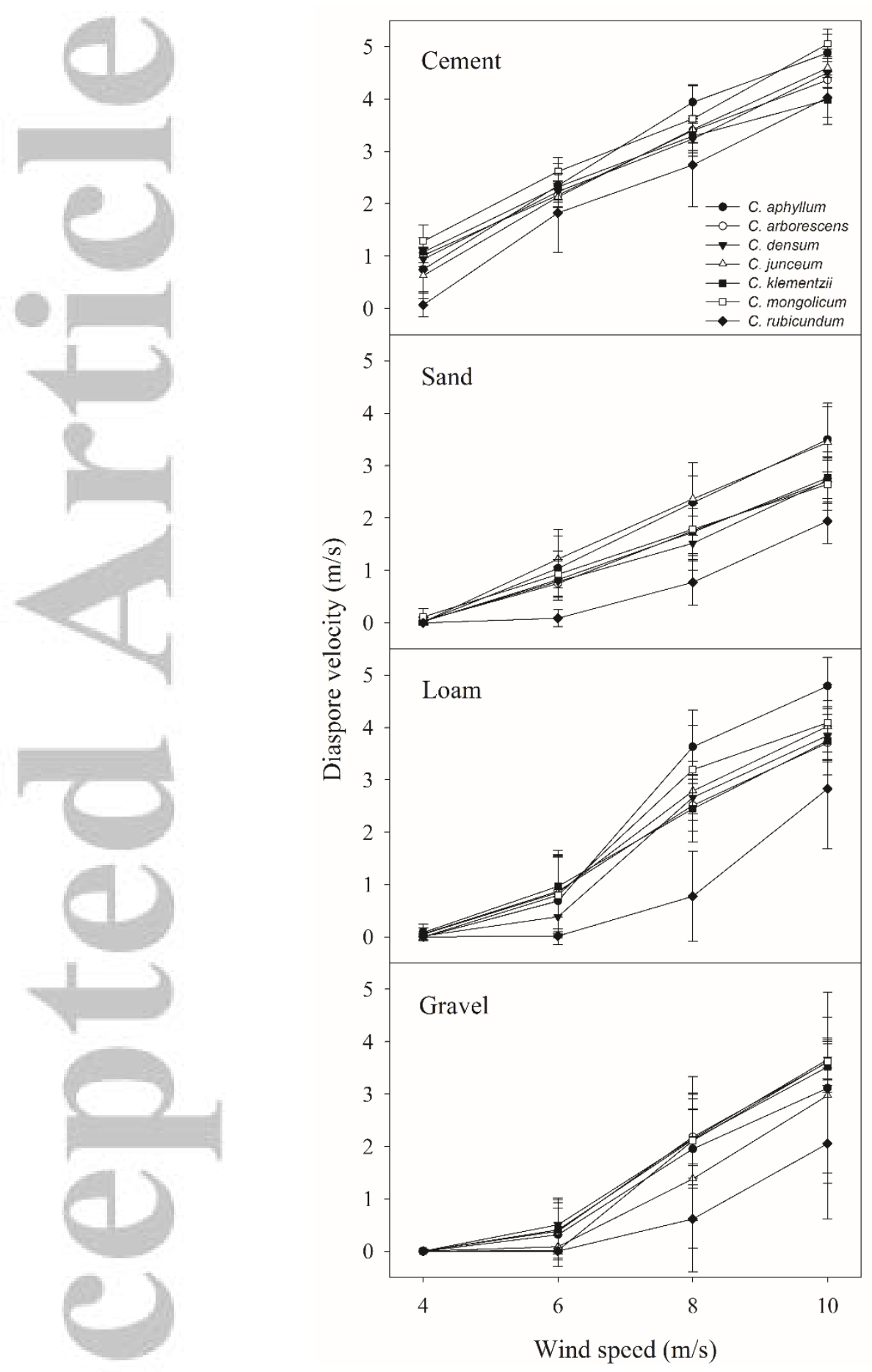

Fig. 6 Diaspore velocity in seven Calligonum species on four types of ground surfaces.

This article is protected by copyright. All rights reserved. 


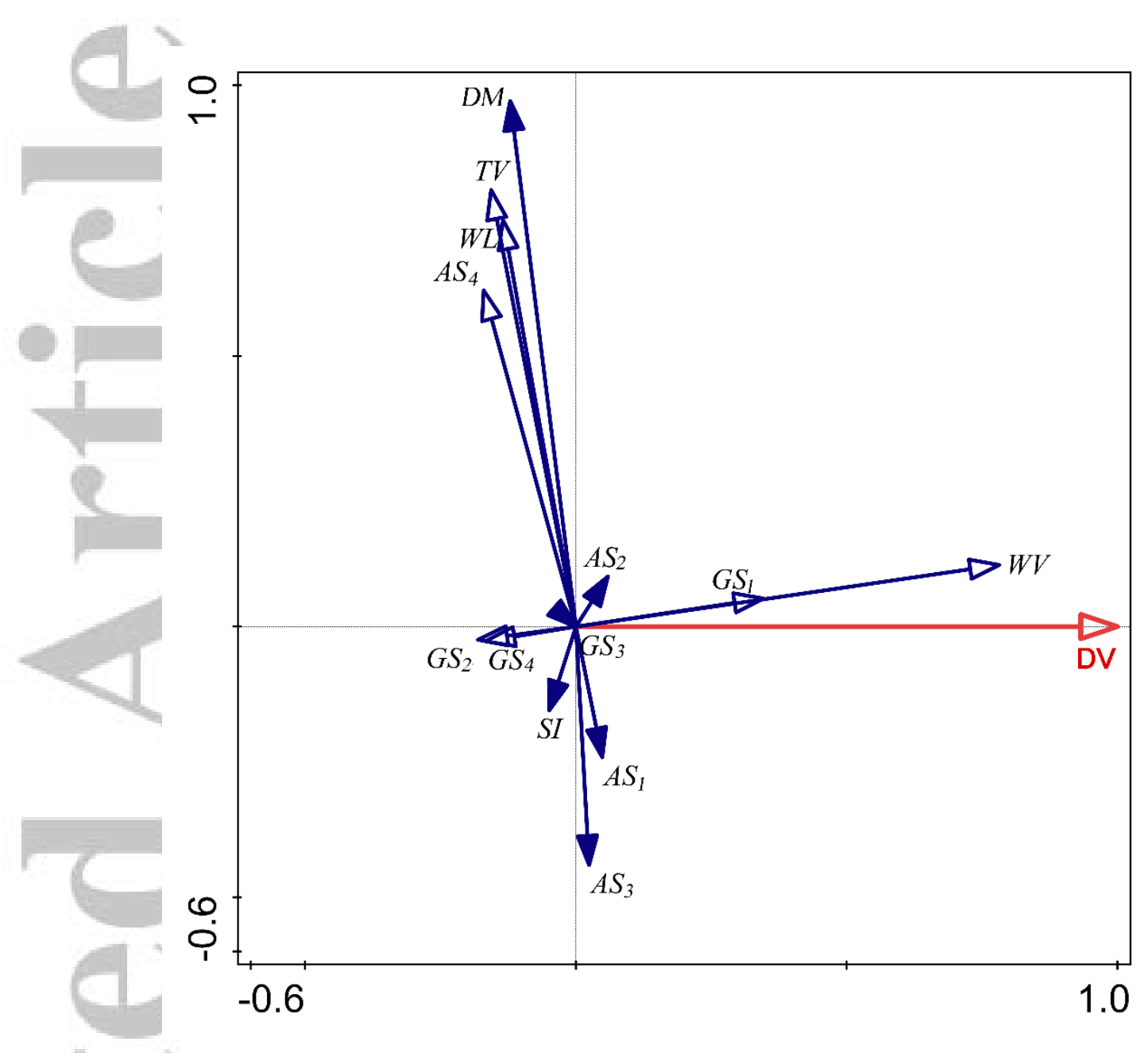

Fig. 7 Relationships between wind velocity, ground surfaces (GS), diaspore morphological traits, and DV. (AS) appendage structures, $\left(\mathrm{AS}_{1}\right)$ wings, $\left(\mathrm{AS}_{2}\right)$ bristles, $\left(\mathrm{AS}_{3}\right)$ balloon, $\left(\mathrm{AS}_{4}\right)$ wings+thorns, $\left(\mathrm{GS}_{1}\right)$ cement, $\left(\mathrm{GS}_{2}\right)$ sand, $\left(\mathrm{GS}_{3}\right)$ loam, $\left(\mathrm{GS}_{4}\right)$ gravel, $(\mathrm{DM})$ diaspore mass (mg), (TV) terminal velocity $(\mathrm{m} / \mathrm{s}),(\mathrm{WL})$ wing loading $\left(\mathrm{mg} / \mathrm{cm}^{2}\right),(\mathrm{SI})$ shape index, and DV $(\mathrm{m} / \mathrm{s})$. Red hollow arrows represent the DV, blue hollow arrows represent significant factors, and blue solid arrows represent non-significant factors. 